\title{
Assistive technologies to address capabilities of people with dementia: from research to practice
}

Paul-Ariel Kenigsberg ${ }^{\mathrm{a}^{*}}$, Jean-Pierre Aquino ${ }^{\mathrm{a}}$, Alain Bérard ${ }^{\mathrm{a}}$, François Brémond ${ }^{\mathrm{b}}$, Kevin Charras ${ }^{\mathrm{a}}$, Tom Dening ${ }^{\mathrm{c}}$, Rose-Marie Droës ${ }^{\mathrm{j}}$, Fabrice Gzil ${ }^{\mathrm{a}}$, Ben Hicks ${ }^{\mathrm{d}}$, Anthea Innes $^{\mathrm{e}}$, Mai Nguyen ${ }^{\mathrm{f}}$, Louise Nygård ${ }^{\mathrm{g}}$, Maribel Pino ${ }^{\mathrm{h}}$, Guillaume Sacco ${ }^{\mathrm{b}}$, Eric Salmon ${ }^{\mathrm{i}}$, Henriëtte van der Roest ${ }^{j}$, Hervé Villet ${ }^{\mathrm{a}}$, Marion Villez ${ }^{\mathrm{a}}$, Philippe Robert ${ }^{\mathrm{b}}$, Valeria Manerab.

a. Fondation Médéric Alzheimer, Paris, France

b. CoBTek, Université de Nice Sophia-Antipolis, France

c. Institute of Mental Health, University of Nottingham, United Kingdom

d. Bournemouth University Dementia Institute, United Kingdom

e. Department of Applied Social Science University of Stirling, United Kingdom

f. Informatics Department, Télécom Bretagne, France

g. Department of Neurobiology, Care sciences and Society, Karolinska Institute, Stockholm, Sweden

h. Laboratoire Lusage, Hôpital Broca, Assistance publique-Hôpitaux de Paris, France

i. Department of Neurology, Liège University Hospital, Belgium

j. Alzheimer Center, VU Medical Center, Amsterdam, The Netherlands

* Corresponding author

Paul-Ariel Kenigsberg, Fondation Médéric Alzheimer, 30 rue de Prony, Paris, France.

Tel 0033156791 789. e-mail : kenigsberg@med-alz.org

\section{ABSTRACT}

Assistive technologies (AT) became pervasive and virtually present in all our life domains. They can be either an enabler or an obstacle leading to social exclusion. The Fondation Médéric Alzheimer gathered international experts of dementia care, with backgrounds in biomedical, human and social sciences, to analyse how AT can address the capabilities of people with dementia, on the basis of their needs. Discussion covered the unmet needs of people with dementia, the domains of daily life activities where AT can provide help to people with dementia, the enabling and empowering impact of technology to improve their safety and wellbeing, barriers and limits of use, technology assessment, ethical and legal issues. The capability approach (possible freedom) appears particularly relevant in person-centered dementia care and technology development. The focus is not on the solution, rather on what the person can do with it: seeing dementia as disability, with technology as an enabler to promote capabilities of the person, provides a useful framework for both research and practice. This article summarizes how these concepts took momentum in professional practice and public policies in the past fifteen years (2000-2015), discusses current issues in the design, development and economic model of AT for people with dementia, and covers how these technologies are being used and assessed.

Keywords: dementia, assistive technologies, capabilities, empowerment, assessment, ethics, human rights, psychosocial model of disability, public policies, economics 


\section{INTRODUCTION}

Due to population aging, the number of people living with dementia - a major cognitive disorder with deficits sufficient to interfere with independence in activities of daily living - is growing every year, representing a major challenge for the healthcare systems (Alzheimer's Disease International, 2014). Dementia can result from different causes, the most common being Alzheimer's disease (AD). Depending on the etiology and the disease stage, dementia can be characterized by cognitive, behavioral, motor and/or functional symptoms. The biological processes involved in dementia are very heterogeneous, including neuroinflammation, gliosis, synaptic loss, neurodegeneration, cerebral atrophy and alterations of the blood-brain barrier permeability (Raz, Knoefel, Bhaskar, 2016). What the different forms of dementia have in common is that they lead individuals to lose the ability to perform independently and successfully everyday tasks (e.g., preparing a meal, taking their own medications, or making a phone call), thus bringing them to a dependency status. As there is no ultimate cure to dementia, research is focusing on one hand on ways to prevent - or at least delay - the dementia onset; and on the other hand, on ways to compensate for the individuals' physical and cognitive deficits, in order to promote their autonomy status, and to improve the quality of life of people with dementia and their caregivers.

Information and Communication Technologies (ICT) can play a role both in preventing cognitive and physical decline (Sacco et al, 2012), and in compensating for existing impairments, for instance through Assistive Technologies. AT include any device or system that allows individuals to perform tasks that they would otherwise be unable to do, or increases the ease and safety with which tasks can be performed (Royal Commission on Long Term Care ${ }^{1999)}$. These devices range from simple 'low tech' items such as calendar clocks, to more complex 'high tech' items such as automatic lighting, telecare sensors and social robots. However, the complexity of technology embedded in a device is less relevant than the ease of use. AT became pervasive, and virtually present in all our life domains, including work (laptop, calculator, smartphone), activities of daily living (microwave, coffee maker, heater), and social and leisure activities (mobile phone, TV, tablet). In all these contexts, AT are meant to simplify our lives, and improve our ability to accomplish complex tasks in an error-free way, eventually compensating for acquired disabilities such as those emerging as a consequence of neurodegenerative diseases. However, while AT are designed to reduce disabilities in older people, they may also represent an obstacle leading to social exclusion if the person is unable to employ AT successfully. For instance, using social networks through a smartphone can improve the social life of older people, allowing them to interact with their grandchildren more often, or to chat with friends. But being unable to use a smartphone can leave them out of the social circle, as more and more communication is made everyday through these ICT devices.

The role of AT in the domain of AD and related disorders is still debated, and the field would benefit from additional analyses. In this paper we will summarize the experience gained in the field of AT, and analyze the framework for their use by people with AD. 


\section{METHODS}

\subsection{Gathering expert insight}

Since 2007, the Fondation Médéric Alzheimer gathers external experts to: a) develop an original, up-to-date, robust and valid conceptual framework on how the future context of dementia may unfold, to enrich strategic thinking; b) engage with uncertainty, within limits of scientific plausibility; c) reframe complex problems, find a shared language, identify research themes; d) enable a multi-disciplinary, open, progressive debate, of high scientific level, to create exchange spaces (research networking); and e) explore promising issues, to produce practical guidelines. Since 2012, the group has met once a year. The thematic area in 2014 was: "Technology \& Alzheimer's Disease". The present article stems from a 1-day, multi-disciplinary expert group discussion initiated in December 2014 and updated in November 2016, with 20 participants from the fields of cognitive neurosciences, computer sciences, economics, ergonomics, geriatrics, neurology, occupational health, philosophy, psychiatry, public health, cognitive psychology, social psychology, social policy, sociology and gerontology. To gather expert insight, several methods were combined. Session started with brainstorming on the needs of a person with Alzheimer's Disease. Then, 10 short oral presentations of 12 minutes each were used to update group knowledge on selected issues, followed by short questions to clarify a precise point. Technologies were discussed within the WHO framework of Functioning, disability and health. In-depth, structured group discussion with a moderator was organized in 4 sequences of 45 minutes. Discussion covered: unmet needs of people with dementia and their caregivers; domains of daily life activities where assistive technology can provide help to people with dementia; the enabling and empowering impact of technology to improve their safety and wellbeing; barriers and limits of use; methods for technology assessment and ethical issues.

To gather further insight, expert discussion was extended, using input from scientific and professional literature. In this article, the angle chosen to present assistive technologies is how they can address the capabilities of people with dementia.

\subsection{The capability approach}

Capabilities are defined as the opportunities that individuals have to achieve particular functionings. They are dynamically shaped by interactions between individuals and their environments, including their social relationships (Entwistle and Watt, 2013). People with dementia appear quite disadvantaged in their possibilities: their capability level (possible freedom) is comparable to that of people without cognitive disorders, but having at least five types of impairments in self-care and participation in domestic life (Tellez, 2016; Le Galès, 2016). It is also known that tailoring activities to the capabilities of dementia patients, and training families in activity use, result in clinically relevant benefits for patients and caregivers (Gitlin et al, 2008). The capability approach, largely diffused by the economist Amartya Sen (Nobel Prize 1998), appears particularly relevant in person-centered dementia care and AT development. The focus is not on the solution, rather on what the person can do with it: seeing dementia as disability, with technology as an enabler to promote capabilities of the person, provides therefore a useful framework for practice. We will analyse how these concepts took momentum in professional practice and public policies in the past fifteen years (2000-2015). We will also discuss current issues in the design, development and economic model of technologies for people with dementia, and how these technologies are used and assessed. 
3.3 The Human Rights based approach for people with cognitive disability

In 2002, the World Health Organization introduced the biopsychosocial model of disability (Fig.2): a biological, individual and social perspective of disability and functioning, where engagement into an activity is influenced not only by the medical condition and possible impairments, but also by contextual factors linked to environment and the person (World Health Organisation, 2002).

The contextual factors explain why it is essential to recognize that each person with dementia is unique: the same assistive technology device may be enabling, useful, useless or irritating depending on the person using it, for whom it is used, and in which conditions. It is also important to consider that incapacities to perform instrumental activities of daily living (IADL), are affected since the stage of mild cognitive impairment (Jekel et al, 2015), and may influence the appropriation and use of technology. The perceived ability to use everyday technology may actually predict overall functional level in people with mild cognitive impairment or mild AD (Ryd, Nygård, Malinowsky, Öhman and Kottorp, 2016). More generally, tool use disorders in neurodegenerative diseases involve impairments in semantic memory and technical reasoning, besides motor capacity (Baumard et al, 2016).

\subsection{The organizational approach}

Industrial issues concerning technology development are discussed under the global approach of the value chain, a set of activities that an organization carries out to deliver a valuable product or service to its customers (Porter, 1985), value being defined as outcomes (ultimately, satisfaction of customer's needs) relative to cost (Porter, 2010).

\section{RESULTS}

4.1 Unmet needs of people with dementia

An important starting point to understand how AT can help people with dementia is to identify their unmet needs. A Dutch survey conducted on 236 community-dwelling people with dementia and 322 informal carers showed that most unmet needs are experienced in the domains of memory (support for memory problems), access to information about dementia, company, psychological distress, daytime activities, and eyesight/hearing (van der Roest et al, 2009). Reported reasons for unmet needs included a lack of knowledge about the existing service offer, a threshold to using services, and insufficient services offer.

\subsection{How can technology help?}

The Technology Charter for People Living with Dementia in Scotland (NHS Scotland, The Scottish Government, Alzheimer Scotland, Scottish Fire and Rescue Service, Tunstall, Tynetec, 2015) identified three ways in which AT can help people with dementia: enabling and empowering; health and wellbeing; safety and independence (Table 1). For each point, we will discuss examples of AT, and explain how they can achieve the identified needs.

\section{a) Enabling and empowering}

In order to maintain a good quality of life, improve self-esteem and mood, it is essential that people with dementia can maintain some autonomy in activities of daily living as long as possible, and maintain a regular social activity. AT can provide useful tools to help people affected by physical and/or cognitive decline in that sense, while reducing caregiver's burden. For example, using a mobile telephone may be possible at an early 
stage of $\mathrm{AD}$ with specific learning techniques based on procedural memory, however after a 3-month rehabilitation scheme (Lekeu, Wojtasik, Van der Linden, Salmon, 2002). An assistive dressing system has been described, which continuously monitors the dressing state of the user, identifies and prompts correct and incorrect dressing states, and provides corresponding cues to help complete the dressing process with minimal caregiver intervention (Burleson, Lozano, Ravishankar, Rowe, Mahoney E, Mahoney D, 2015). A growing AT area is that of socially assistive robots, which are perceived as useful solutions by people with dementia and their caregivers (Pino, Boulay, Jouen, Rigaud, 2015). Despite several remaining usability problems, socially assistive robots represent promising solutions to assist with communication and reduce the impact of sensory loss, to reduce isolation and disconnection from personal and social communities, and to support the ordinary activities of daily life (Kramer et al, 2009; Tanaka et al, 2012; Mordoch et al, 2013). Communication can also be improved by using avatars, i.e., computer programs able to interact with users thanks to user inputs acquired through a set of sensors (cameras, microphones, touch screen, etc.) and a virtual character. Current applications are able to produce human-like communication behaviors by speaking and gesturing, and can be used also to assess people's cognitive status (Nonaka, Sakai, Yasuda, Nakano, 2012).

\section{b) Health and wellbeing}

The area of AT to improve safety and wellbeing is expanding, as evidence about the effectiveness and acceptability of AT for therapeutic purposes is increasing. For instance, several studies have been recently carried out on the use of serious games videogames designed for purposes other than entertaining - for the cognitive and physical stimulation of patients with $\mathrm{AD}$ and related disorders (Robert et al, 2014). Several serious games targeting cognitive stimulation (e.g., multi-tasking ability) have been shown to improve cognitive functions in healthy elderly people (Anguera et al, 2014) and studies are now extending to pathological populations. For instance, Ben Sadoun and colleagues (2016) showed that $X$-Torp, a serious game designed to combine cognitive and physical stimulation, is well accepted and positively evaluated by both healthy elderly people and patients with MCI and early stages of AD. These studies suggest that serious games may represent a useful motivational tool to create entertaining trainings for patients with dementia-related disorders, to be used to complement standard pharmacological treatments. In 2017, the X-Torp game was granted the status of medical device (Class 1-93/42/CE) from the French health authorities. Gamers will access the game via an Internet platform. Virtual reality (VR) is now seen as another promising tool to create motivational trainings (Rizzo and Kim, 2005). VR cognitive trainings designed for people with dementia are generally well accepted, and preferred over classical paper pencil exercises even by dementia participants with scarce previous experience with ICT devices (Manera et al, 2016). Beyond supporting physical and mental health and wellbeing, VR can also be employed to support reminiscence and life story work. In a recent study we have shown that VR is a promising tool to improve reminiscence therapy in the elderly (Benoit et al, 2015): thanks to a high level of immersion in the virtual environment, which generates a feeling of presence, VR can successfully help triggering old memories. An emerging trend, which has recently generated a large public interest worldwide, is the use of VR on a mobile serious game (Sea Hero Quest) to collect a normative data set in healthy people to create a diagnostic test based on spatial navigation skills. This would help understand how the early symptoms of dementia can be differentiated from the consequences of 
natural ageing, to develop dementia prevention strategies and early interventions using gaming technologies (Morgan, 2016).

AT supporting the search for information, advice, support and help are also emerging, targeting both people with dementia and their formal and informal caregivers. AT in this domain include both serious games designed for caregiver training (Manera et al., submitted); web-based blogs and platforms to facilitate and improve the communication between caregivers and healthcare professionals (Span et al, 2015); websites designed to provide information on dementia-related disorders targeting caregivers, patients with dementia and professional organizations, such as DEM-DISC, a dynamic interactive social chart for dementia care (Droës et al, 2005); and e-learning platforms for carers, volunteers, and professionals, such as Star course (Hattink et al, 2015).

\section{c) Safety and independence}

Several AT designed to improve safety and independence are already available on the market, and others are being developed. Social alarms can be defined as "devices (with or without some intelligence) located in the home, which, when activated, facilitate communication with a responder and the sending of information relevant to the user's well-being" (Fisk, 2003). These include smart smoke, gas and carbon monoxide detectors, which can be wireless connected and in case of an accident can alert people in the neighborhood through loud alarms, as well as local fire services and caregivers through automatic phone calls and text messages. The connected devices can be checked remotely for proper functioning (e.g., are they plugged in correctly? Is the battery charged? etc.). A survey conducted in England and Scotland confirmed that over $70 \%$ of elderly people have some form of social alarms installed in their homes, and that they are considered as generally acceptable (McCreadie and Tinker, 2005). These social alarms can help both to reduce the risk of fire and other common home accidents, and to automatically alert a remote partner in care to the real time occurrence of a risk to the person or property. Similar functions are covered by connected video monitoring systems. Thanks to automated video analyses techniques, video and RBD cameras can be employed to automatically detect accidents such as falls. Interestingly, algorithms are being developed to use cameras to improve the ecological assessment of activities of daily living (ADL) of older people. In the context of the European FP7 project Dem@Care, algorithms have been developed for the recognition and classification of everyday activities, such as sitting and waking up, preparing a meal, or going to bed (see Figure 1). Results collected on participants with mild cognitive impairment and dementia suggest that these algorithms are sensitive enough to accurately discriminate different ADL activities when participants follow a pre-defined activity scenario (König et al, 2015). They may therefore contribute significantly to home safety by creating personalized solutions enabling older adults to live longer, autonomously in their preferred environment.

Customized solutions are also being developed to support people with dementia to walk freely and safely both indoors and outdoors, to encourage them to go out and about, while reducing the risk of being lost and associated risks, and to facilitate communication of the person with dementia with a remote partner in care, should clarity or reassurance be required. For instance, the COGKNOW Day Navigator (Meiland et al, 2012), developed in a FP6 European project, is a holistic solution that assists persons with dementia within their own homes and outside. It increases independence and quality of life, while giving caregivers the relief of not having to monitor the person with dementia all the time. The service can be easily customized to address the individual needs of each person and their caregivers, for memory support, helping with 
daily activities, maintaining social contacts and increased safety. The main functionalities are: time indication, remotely configurable reminders, music, radio, picture dialing, activity assistance, house alerts for safety, and mobile navigation for going home.

\subsection{How can technology be an obstacle?}

Despite that an AT can simplify daily life and compensate for disability in several ways, it can sometimes be an obstacle and lead to exclusion, when people are unable to afford it, learn how to use it, or forget how to use it (Damant and Knapp, 2015). As AT is so pervasive in our everyday life, it would be important to include assessment of AT use in the clinical assessment instruments. However, despite technology has changed our everyday activities, ADL/IADL assessment instruments remained mostly the same. For this reason, new clinical instruments assessing the ability to use everyday technology are being developed. The Everyday Technology Use Questionnaire (ETUQ; Rosenberg, Kottorp, Winblad and Nygård, 2009; Nygård, Pantzar, Uppgard and Kottorp, 2012), was designed to assess perceived difficulty in using everyday technology. Similarly, the Management of Everyday Technology Assessment (META; Malinowsky, Nygård and Kottorp, 2011), evaluates the observed ability to manage everyday technology. Studies employing these instruments have shown that people with dementia and MCI have a greater difficulty to employ some everyday technologies, and thus the evaluation of AT actual use may be a sensitive way to detect early changes in cognitive decline (Ryd, Nygård, Malinowsky, Öhman and Kottorp, 2016). Specifically, it is possible to create a hierarchy of action skills needed when handling everyday technology. This knowledge can be applied to design or adapt devices to reduce difficulty of use by people with cognitive impairment. Patomella and colleagues $(2011,2013)$ have found that a technology is considered more difficult to use when: it is used less than once a week, has more complex design, requires more actions, requires that actions are used more frequently, and that more difficult actions are used more frequently, requires that actions are taken in particular sequences, gives more complex, mostly visual feedback and uses abstract symbols. Interestingly, this perceived difficulty appears independent of the user's age, gender, and of how long the AT had been used. The same authors found that many different aspects influence whether a piece of technology will be appropriated and used or not. These include the interests and attitudes of the person and the social context; the person's ability to use the technology; the level of challenge of the technology; and the context.

\subsection{Design and development of technologies for people with dementia}

Combining ICT and the social environment of older people, to support a widely selfdetermined autonomous life in their own homes, has led to the development of concepts, products and services for their daily life, under the European research programme Ambient Assisted Living (AAL; Siegel, Hochgatterer and Dorner, 2014). From 2008 to 2013 , over 130 projects were launched, leveraging 620 million euros. But only a handful of solutions made it to market. This is largely explained, on one hand, by the difficulty to find a viable industrial business model, and on the other hand by the inadequation of these solutions to the real needs of end users. Although these solutions are not specific for people with cognitive disorders, they surround them and will challenge them over time in their everyday life (Rosenberg and Nygård L, 2014). Three distinct research and development approaches can be observed, with distinct objectives and stakeholders involved. First, research on technologies specifically designed for people with dementia, mostly driven by multi-disciplinary academic/industrial teams and funded by 
national or international grants, usually results in the production of prototypes to demonstrate practical feasibility and attract further research funding. An example of such upstream research is a validated automatic video monitoring system for the detection of instrumental activities of daily living in people with dementia (König et al, 2015). A second approach is to adapt existing technologies to new potential usage by people with dementia, usually funded by technology industrials seeking first sales or commercial target extension, with eventual support from local or regional partners. To gain customer confidence, technologies are usually tested in reference centers before being promoted at a larger scale. For example, programs combining the use of GPS bracelets, databases of people with dementia and police training have been effective in locating missing people faster (Petonito et al, 2013). A third approach is to adapt the competence of people with dementia to use everyday technology, i.e. electronic, technical and mechanical equipment, newly developed or common and well-known, in their living environment. Key professionals involved are occupational therapists and neuropsychologists. Family and volunteers may provide useful assistance to people with dementia about using the technology. One example is the use of recreational games: people with dementia, engaging with digital gaming technology in Tech Clubs, were able to challenge informal and formal caregivers' perceptions of their abilities (Cutler, Hicks and Innes, 2016). Other examples include the use of existing electronic pads or music playing devices for reminiscence interventions or recreational purposes; and serious games, which stimulate executive functions and foster engagement in people with dementia, apathetic or not, while providing a pleasurable activity. Success or failure of these different approaches depends whether products are adapted to the capacities of people with dementia, respond to actual needs of the persons and caregivers, are endorsed by Alzheimer's associations and scientific societies, and provide relevant support services with a human assistance at the end.

Co-design of technologies with advice from people with dementia and their caregivers is an emerging trend (Span, Hettinga, Vernooij-Dassen, Eefsting and Smits, 2013). In understanding the limitations experienced by people with dementia, co-design activities allow developers to reduce challenges introduced by technology use, while empowering the persons. A positive impact is the increased caregivers awareness of their remaining abilities and reducing the potential of a person to be seen as a victim (Jury, 2016; Swaffer, 2014). AAL environments can be designed to support informal caregivers in fashioning "do-it-yourself" solutions that complement tacitly improvised care strategies and enable them to try, observe, and adapt to solutions over time, decide which activities to entrust to technology support, how a system should provide support and when adaptations are needed (Hwang, Truong, Cameron, Lindqvist, Nygård and Mihailidis, 2015).

\subsection{Usages and appropriation of technologies by people with dementia}

Within the biopsychosocial model of disability, technology can be viewed as an enabling tool to promote autonomy and citizenship of a person with dementia throughout daily life activities. Technology has multiple purposes, which can be summarized in a simple way, using the standards of the WHO International Classification of Functioning, Disability and Health (World Health Organisation, 2002). Nine domains of daily life activity appear relevant for technology: earning and applying knowledge; general tasks and demands; communication; mobility; self-care; domestic life; interpersonal interactions and relationships; community, social and civic life; recreation and leisure (Table 3). Learning how to use technologies is key, given their multitude and ever-changing designs. How people with dementia strive to learn and 
maintain their skills and knowledge related to technology deserves further attention. A pilot study, involving people with mild to moderate stage dementia, suggests that they use different ways of learning in their daily life, relying on one's habituated repertoire of actions, on other people or on technology itself, or belonging to a learning context (Rosenberg and Nygård, 2016).

\subsection{Ethical, financial and legal issues}

Key ethical issues concern privacy, decision-making about the use of technology by people with dementia and financial access to technologies. In a guidance issued in 2015, the Mental Welfare Commission of Scotland states that "efforts must always be taken to support someone to make a decision whenever this is possible. This may include taking extra time to explain what is being proposed, involving advocacy, and using communication aids to help promote discussion and understanding." Advance planning can help to gather adequate willingful consent from the person with dementia about technology use, before severe cognitive impairments preclude this consent (Yang and Kels, 2016). Concerning financial access from a consumer perspective, cost of technology must include acquisition and rental costs, plus support and maintenance costs. AT services are subject to major variations in pricing in a mixed economy of multiple dementia care providers, including primary care, local authorities, private companies and local or national resources dedicated to assistive technologies (Gibson et al, 2016). Solvency of consumers is key to facilitate purchase of AT, and can partly be compensated by public policies. Affordability of technology can been quantified using willingness to pay approaches. A recent survey of American caregivers of older people showed that the mean amount they are willing to pay is approximately $\$ 50$ per month for monitoring technologies and $\$ 70$ per month for technologies that would both monitor and provide some assistance (Schulz et al, 2015). Younger caregivers, those caring for a person with $\mathrm{AD}$, and caregivers with more positive attitudes toward and experience with technology are willing to pay more. However, $20 \%$ of the caregivers are not willing to pay anything. Most caregivers expect some financial help from the government or private insurance to have access to technologies. Ethical issues for equal access to technologies therefore involve some part of collective funding, eligibility of users being based on individual financial and social situation.

Key legal issues in using technology concern primarily contract obligations (who should be deemed responsible in case of device or support failure causing harm to the user?), conformity of technology to human rights and individual data sharing, both in research and practice. The use of mass data for research generated by monitoring behaviours in smart homes and serious games on mobile phones constitute a novel issue. The first large-scale in-home monitoring using pervasive computing technologies to give continuous access to AD progression and intervention efficacy has been installed in Oregon (United States) in 500 homes, collecting data for up to 8 years on gait and mobility, sleep and activity patterns, medication adherence, and computer use (Lyons et al, 2015). Patterns of intra-individual variation detected in each of these areas are used to predict outcomes such as low mood, loneliness, and cognitive function. The web game Sea Hero Quest intends to collect a normative data set on healthy people worldwide, to help create a cognitive diagnostic test based on spatial navigation skills. It may boost research on prevention of dementia by identifying early, subtle behavioural, cognitive and executive changes, in a "massive online citizen science experiment" able to test 200 people in 1 minute (Morgan, 2016). Altogether, the development of a legal framework for AT in dementia remains a complex endeavor. It 
has been set as a long-term challenge (2020-2030) by the Japan Advanced Institute of Science and Technology (Sugihara, Fujinami, Phaal and Ikawa, 2015).

4.7 Valuing technologies for people with dementia: assessment and economic model From a person-centered approach, a technology has a value if it satisfies the needs of people with dementia and their caregivers, at an individual level. But who assesses how technology and related technology support services satisfy these needs? From an organizational point of view, the value chain of AT for people with dementia can be broadly described using 10 basic processes: research, industrial development, production, marketing, distribution, technology assessment, prescription, purchase (copayment), device use, data sharing, user assistance and device maintenance. These processes involve multiple professionals from many different cultures, with no clear identification of who is concerned with individual needs and technology use assessment (Table 4). The overall economic model is not yet stabilized and depends in part of collective funding to facilitate access to AT. In this emerging field, industrials are moving towards norms and quality labels of technology solutions to increase confidence of potential users, that these devices will satisfy their needs. Some Alzheimer's associations and people with dementia have started hands-on demonstration of technology devices that may be of interest. Technology assessment also involves opinion leaders running clinical trials, professional societies, care operators, central purchasers, public funders. Occupational therapists could give relevant individual advice, as they know about activity limitations of people with dementia, if properly informed, trained and engaged in technology assessment (Jarvis, Clemson and Mackenzie, 2016). A predictive model to differentiate between adopters and nonadopters of everyday technology aimed at people with dementia has been described (Chaurasia $\mathrm{P}$ et al, 2016). Validated tools for assessing the ability to use everyday technology in a standard way, such as the Everyday Technology Use Questionnaire (ETUQ; Rosenberg, Kottorp, Winblad and Nygård, 2009; Nygård, Pantzar, Uppgard and Kottorp, 2012), and the Management of Everyday Technology Assessment (META; Malinowsky, Nygård and Kottorp, 2011) deserve a larger diffusion in clinical practice (Nygård, Kottorp and Rosenberg, 2015).

From a broader perspective, should society as a whole invest in AT for people with dementia? In other terms, does AT for people with dementia bring social innovation, which means a novel solution to a social problem that is more effective, efficient, sustainable, or just than current solutions? If so, the value created would accrue primarily to society rather than to private individuals (Phills, Deiglmeier and Miller). The approach of social return on investment is emerging. For example, in England, lifetime costs of dementia, including publicly and privately financed health and social care, average 200,000 sterling pounds per person and per year from diagnosis to endof-life. A technology, along with accompanying assessment and services, would be costeffective from a societal perspective if it either reduced unpaid care hours by about $8 \%$ or improved caregiver quality of life by 0.06 to 0.08 quality-added life-years (QALYs) per year (Knapp, 2016). 


\section{DISCUSSION}

Development of assistive technology to address capabilities of people with dementia has been shaped in the past decade by major conceptual shifts about daily-life risk perception; viewing dementia as a (potential) disability, which led to enable and empower people with dementia; a more positive communication about technologies, putting benefits forward; and understanding the appropriation process of assistive technology, building on the individual experience of people with dementia.

\subsection{Changes in daily-life risk perception}

Performing an activity of daily life may expose the person with dementia to a number of hazards, minor or harmful. Technology may reduce the occurrence of such events. Within a decade (2005-2015), the notion of risk has evolved and broadened: new expressions emerged, such as positive risk-taking and risk enablement, to account for potential benefits as well as disadvantages upon risk evaluation, to distinguish risk from danger. As the British Department of Health stated in a landmark risk guidance for people with dementia titled: "Nothing ventured, nothing gained", risks must be balanced with opportunities that are likely to follow risk-taking (Department of Health, 2010). However, professionals, carers, and people with dementia consider risk differently. Understanding different ideas about risk is the first step in developing an effective risk mitigation strategy. Decisions about risk should not assume that all people with dementia are "at risk" but should be based upon understanding of individuals and their own understanding of the risks they may face.

Much early research and communication about technology in dementia care has covered barriers to be overcome, raising concerns about potential detrimental effects, such as intrusion on privacy, stigma (with reference to tracking devices), reduced human contact, or reduced use of paid caregiving. According to the Nuffield Council of Bioethics, these issues have the potential to affect both a person's autonomy, for example through feeling controlled or devalued, and their well-being, for example through impoverished human relationships. Where the persons with dementia have the capacity to choose for themselves whether to accept or refuse a particular technology, their decision should be respected. Where a person with dementia lacks the capacity to decide for themselves whether to make use of a particular technology, the relative strength of a number of factors should be considered on an individual basis, including the person's own views and concerns, past and present, the actual benefit which is likely to be achieved through the use of technology, and the extent to which the caregiver's interests may be affected (Nuffield Council of Bioethics, 2009).

\subsection{Dementia as a (potential) disability}

In 2010, the European Dementia Ethics Network stated that it was essential to recognize dementia as a disability (or potential disability), as the first step towards ensuring the appropriate design of assistive technology to be used by or for people with dementia, and towards ensuring that people with dementia have access to it when it would be of most benefit to them (European Dementia Ethics Network, Alzheimer Europe, 2010). Persons with disabilities include "those who have long-term physical, mental, intellectual or sensory impairments which, in interaction with various barriers, may hinder their full and effective participation in society on an equal basis with others", according to the United Nations Convention on the Rights of Persons with Disabilities, an international legal framework ratified by 163 countries. This Human Rights based approach for people with cognitive disability is a new policy currently being promoted 
by the advocacy group Dementia Alliance International, chaired by Kate Swaffer, a young Australian woman living with dementia, and Alzheimer's Disease International (Dementia Alliance International, 2016). However, only a small number of countries do legally recognize dementia as being a disability, which would facilitate access for people with dementia to appropriate support, including assistive technologies. In most countries, disability allowance is actually considered as a compensation benefit for people who are unable to work as a result of their incapacity. As dementia usually develops far beyond the legal limit of working age, the disability approach is rarely considered for them. Scotland has been the first country to have included people with dementia in its implementation of this UN Convention and to have appointed in 2002 a Scottish Dementia Working Group of people with dementia to advise the government, with the support of Alzheimer's Scotland.

\subsection{A positive approach to assistive technology for people with dementia}

In 2015, the Technology Charter for people living with dementia in Scotland introduced a globally positive approach to technology for people with dementia and their partners, putting benefits forward: enabling and empowering, health and well-being, safety and independence (NHS Scotland, The Scottish Government, Alzheimer Scotland, Scottish Fire and Rescue Service, Tunstall, Tynetec, 2015). Developed in consultation with people with dementia, it provides a general framework, easy to understand for all stakeholders, setting up values and principles as a guide to take position on ethical dilemmas. It stems from a dual perspective: the rights of the people living with dementia, and the commitment and responsibility from the care partners (Table 2). This approach is supported by notions of positive and shared risk-taking, freedom of choice, acknowledgement of strengths and experience of the person with dementia. The Charter also states that technologies in all their forms and applications are an integral part of life today, not just because they are available, but because people find them useful.

\subsection{Usage and appropriation of assistive technology by people with dementia}

Yet, few professionals are studying usages of technology, and how people with dementia appropriate it for themselves. A recent review of commercially available AT for people with dementia identified 171 products and 331 services, which can be grouped in products used "by" people with dementia, "with" them or "on" them (Gibson $\mathrm{G}$ et al, 2016).

More and more, people with dementia express themselves on blogs: most of them use non-specific technologies, such as smartphones or computers, generally with a positive experience. Negative experiences are about remembering passwords, or the purpose of the different alarms. Under stress conditions, people with dementia tend to disregard AT devices sensory cues (Teipel et al, 2016). Caregivers also use non-specific technologies, such as electronic pads, baby monitoring systems, smartphones, light sensors, pillows equipped with loudspeakers. Furthermore, technologies change all the time and may be perceived as more difficult to use by people with dementia (Malinowski, Kottorp, Patomella, Rosenberg and Nygård, 2015). A major barrier to technology use is therefore the difficulty to obtain counseling and support (Knapp 2016). In-depth interview with people with mild cognitive impairment show that persons with mild cognitive impairment may relate to technology in various ways to meet needs of downsized doing, but are reluctant to adopt video-based monitoring technology intended to support valued occupations (Hedman, Lindqvist and Nygård, 2016). People with dementia living in institution appear ambivalent about surveillance technology: on one hand, it gives them freedom to venture into new spaces; on another hand, they may be reluctant to use the 
technology provided, as they do not like to be observed (Niemeijer, Depla, Frederiks and Hertogh). Concerning recreational use of technologies, a key outcome is the pleasure of people with dementia as a positive experience: pleasure of being enabled, pleasurable moments with significant others, pleasure of just enjoying, playing and having fun. The use of robotic animals may be beneficial, when introduced prudently after in-depth discussion with persons with cognitive disorders and families, to anticipate potential ethical dilemmas that may arise about values such as honesty, dignity, well-being and personal choice (Gzil, 2015).

An emerging issue concerns the use of technology to create simulated, fictitious environments for reminiscence purposes, aimed at reducing anxiety and stress of people with dementia, such as a virtual reality forest (Moyle W, Jones C, Dwan T and Petrovich $\mathrm{T}$ ), or a fake vintage train station and compartment, with a large television screen as a window, to create the illusion of a real railroad journey. Among people with dementia, the prevalence of those living with different realities and beliefs varies greatly from around $20 \%$ to $70 \%$, in small part depending on the type of dementia a person has (Stokes and Kousoulis, 2017). Dilemmas with carers arise when the two realities meet. Truth or untruths can both cause unnecessary distress, but they can also create joy or necessary negative emotions. Approach must be flexible : person first, intervention second. Each perceived reality shall be explored with the carer, to make sense of the world together (Williamson and Kirley, 2014).

Access to technologies involves information, hands-on testing and learning, rapid and flexible procurement, and affordability. In the perspective of people with dementia and their caregivers, Alzheimer's Scotland has developed an initiative to find, test and share information about domestic products to help people with dementia (clocks, telephones, mobile applications etc.) These products are tested by the persons themselves and exposed in the resources centers of the association (Gray, 2016). Learning and using everyday technology are intertwined processes. It is therefore important to support continued use of everyday technology as long as it is valued and relevant to the person with mild cognitive impairment or Alzheimer's disease (Rosenberg and Nygård, 2014). Rapid and flexible procurement of assistive technology is required to provide a timely response to the changing needs of people with cognitive disability at the different stages of severity (European Dementia Ethics Network. Alzheimer Europe, 2010).

Finally, two outstanding examples of usage and appropriation of technologies to empower people with dementia, on an individual and collective level, are worth mentioning. On an individual level, Masahiko Sato (2014), in the first book ever written by a person with dementia in Japan, explains how, diagnosed with early-onset AD in 2005, he was able to live actively and independently during ten years before moving to a retirement home in 2015, partly thanks to assistive technology. He had worked as a systems engineer for a computer company before his diagnosis. He started using social media and an iPad a few years after he was diagnosed with Alzheimer's disease. He made it a habit to turn his computer on and check his Google calendar when he gets up every morning, not to lose track of time. Before he goes out, he sets several timers on his mobile phone around the scheduled appointment. Using a train timetable and route finder software, he makes sure he gets an alert on his phone while on the train so he won't forget where to get off. He has more than 1,300 friends on Facebook, and makes frequent speeches around the country to share his experience. He recommends that other patients start using such tools in the early stages of their illness. On a collective level, Dementia Diaries is a UK-wide project that brings together people's diverse experiences of living with dementia as a series of audio diaries. It serves as a public record and a personal archive that documents the day-to-day lives of people living with dementia, 
with the aim of prompting a richer dialogue about the varied forms of the condition. Project uses 3D-printed mobile handsets which are customised to be as simple as possible (Woodall, Surr, Kinsella and Bunyan, 2016).

\section{CONCLUSION}

Assistive technologies are part of a global approach of non-drug interventions in dementia care. They deserve further attention in both research and practice. Within a psychosocial model of disability, AT can be viewed as an enabling tool to promote autonomy and citizenship of a person with dementia throughout daily life activities, in a positive way. This approach has started to influence public policies. Knowledge about these technologies must be developed among family and professional caregivers. Design and adaptation of AT must be based on individual needs of people with dementia. Validated tools for assessing the ability to use everyday technology by people with dementia deserve diffusion in professional practice. To be effective and respectful of people with dementia, technological innovation must build upon social innovation, with increased input from human and social sciences. 


\section{REFERENCES}

Alzheimer's Disease International. World Alzheimer Report 2014, Dementia and Risk Reduction, an analysis of protective and modifiable factors. Report. 2014. London (England). www.alz.co.uk/research/WorldAlzheimerReport2014.pdf. Accessed on February 10, 2016.

Anguera JA, Boccanfuso J, Rintoul JL, Al-Hashimi O, Faraji F, Janowich J, Kong E, Larraburo Y, Rolle C, Johnston E, Gazzaley A. Videogame training enhances cognitive control in older adults. Nature 2014; 501 97-102.

Baumard J, Lesourd M, Jarry C, Merck C, Etcharry-Bouyx F, Chauviré V, Belliard S, Moreaud O, Croisile B, Osiurak F, Le Gall D. Tool use disorders in neurodegenerative diseases: Roles of semantic memory and technical reasoning. Cortex 2016; 82: 119132.

Benoit M, Guerchouche R, Petit PD, Chapoulie E, Manera V, Chaurasia G, Drettakis G, Robert P. Is it possible to use highly realistic virtual reality in the elderly? A feasibility study with image-based rendering. Neuropsychiatr Dis Treat 2015; 11:557-563.

Ben-Sadoun G, Sacco G, Manera V, Bourgeois J, König A, Foulon P, Fosty B, Bremond F, d'Arripe-Longueville F, Robert P. Physical and Cognitive Stimulation Using an Exergame in Subjects with Normal Aging, Mild and Moderate Cognitive Impairment. J Alz Dis 2016; doi: 10.3233/JAD-160268.

Burleson W, Lozano C, Ravishankar V, Rowe J, Mahoney E, Mahoney D. Assistive Dressing System: A Capabilities Study for Personalized Support of Dressing Activities for People Living with Dementia. iProc 2015; 1(1):e13. doi:10.2196/iproc. 4700.

Chaurasia P, McClean SI, Nugent CD, Cleland I, Shuai Zhang, Donnelly MP, Scotney BW, Sanders C, Smith K, Norton MC, Tschanz J. Technology adoption and prediction tools for everyday technologies aimed at people with dementia. Conf Proc IEEE Eng Med Biol Soc 2016; 2016:4407-4410.

Cutler C, Hicks B, Innes A. Does digital gaming enable healthy aging for communitydwelling people with dementia? Games and Culture, 2016; 11 (1-2), 104-129.

Damant J, Knapp M. What are the likely changes in society and technology which will impact upon the ability of older adults to maintain social (extra-familial) networks of support now, in 2025 and in 2040. Future of an ageing population: evidence review. Foresight. London: Government Office for Science. May 2015.

Dementia Alliance International. The Human Rights of People Living with Dementia: from Rhetoric to Reality. May 16, 2016. www.dementiaallianceinternational.org/wpcontent/uploads/2016/04/The-Human-Rights-of-People-Living-with-Dementia-fromRhetoric-to-Reality.pdf.

Department of Health. Best Practice Guidance. Nothing ventured, nothing gained: risk guidance for dementia. 2010.

Dröes RM, Meiland FJ, Doruff C, Varodi I, Akkermans H, Baida Z, Faber E, Haaker T, Moelaert F, Kartseva V, Tan YH. A Dynamic Interactive Social Chart in Dementia Care 
Attuning Demand and Supply in the Care for Persons with Dementia and their Carers. Stud Health Technol Inform 2005; 114: 210-220.

Entwistle VA and Watt IS. Treating Patients as Persons: A Capabilities Approach to Support Delivery of Person-Centered Care. Am J Bioeth. 2013 Aug; 13(8): 29-39.

European Dementia Ethics Network. Alzheimer Europe. The ethical issues linked to the use of assistive technologies in dementia care. 2010. www.alzheimereurope.org/Ethics/Ethical-issues-in-practice/The-ethical-issues-linked-to-the-use-ofassistive-technology-in-dementia-care.

Fisk, MJ. Social Alarms to Telecare: Older People's Services in Transition. 2003. Bristol: Policy Press. 304 pp. ISBN 978-1-8613-4506-6.

Gibson G, Newton L, Pritchard G, Finch T, Brittain K, Robinson L. The provision of assistive technology products and services for people with dementia in the United Kingdom. Dementia (London) 2016; 15(4): 681-701.

Gitlin LN, Winter L, Burke J, Chernett N, Dennis MP, Hauck WW. Tailored Activities to Manage Neuropsychiatric Behaviors in Persons With Dementia and Reduce Caregiver Burden: A Randomized Pilot Study. Am J Geriatr Psychiatry 2008; 16(3): 229-239.

Gray J. A guide to Alzheimer Scotland's development and innovation work. Dementia in Scotland 2016; 89: 21.

Gzil F. Commentary on vignette 5, the situation involving George and his cat. In Ethical dilemmas faced by health and social care professionals providing dementia care in care homes and hospital settings. A guide for use in the context of ongoing professional care training. Dementia in Europe Ethics Report 2015. Luxembourg: Alzheimer Europe $2015 ; 25-27$.

Hedman A, Lindqvist E, Nygård L. How older adults with mild cognitive impairment relate to technology as part of present and future everyday life: a qualitative study. BMC Geriatrics (2016) 16:73.

Hwang AS, Truong KN, Cameron JI, Lindqvist E, Nygård L, Mihailidis A. CoDesigning Ambient Assisted Living (AAL) Environments: Unravelling the Situated Context of Informal Dementia Care. Biomed Res Int 2015; 2015:720483.

Hattink B, Meiland F, van der Roest H, Kevern P, Abiuso F, Bengtsson J, Giuliano A, Duca A, Sanders J, Basnett F, Nugent C, Kingston P, Dröes RM. Web-Based STAR ELearning Course Increases Empathy and Understanding in Dementia Caregivers: Results from a Randomized Controlled Trial in the Netherlands and the United Kingdom. J Med Internet Res 2015; 17(10):e241. doi: 10.2196/jmir.4025.

Jarvis F, Clemson LM, Mackenzie L. Technology for dementia: attitudes and practices of occupational therapists in providing assistive technology for way finding. Disabil Rehabil Assist Technol 2016; DOI:10.3109/17483107.2016.1173729.

Jekel K, Damian M, Wattmo C, Hausner L, Bullock R, Connelly PJ, Dubois B, Eriksdotter M, Ewers M, Graessel E, Kramberger MG, Law E, Mecocci P, Molinuevo 
JL, Nygård L, Olde-Rikkert MG, Orgogozo JM, Pasquier F, Peres K, Salmon E, Sikkes SA, Sobow T, Spiegel R, Tsolaki M, Winblad B, Frölich L. Mild cognitive impairment and deficits in instrumental activities of daily living: a systematic review. Alz Res Ther 2015; 7(1): 17.

Jury R. Not for me, without me. Co-designing assistive technology with people affected by dementia. Master's Thesis. School of Art and Design. Auckland University of Technology 2016.

Knapp M (coord.). The case for investment in technology. Policy Innovation Research Unit. Publication 2016-2018. 124 p. 2016.

König A, Crispim Junior CF, Derreumaux A, Bensadoun G., Petit PD, Bremond F, David R, Verhey F, Aalten P and Robert P. Validation of an Automatic Video Monitoring System for the Detection of Instrumental Activities of Daily Living in Dementia Patients. J Alz Dis 2015; 44: 675-685.

Kramer SC, Friedmann E, Bernstein PL. Comparison of the Effect of Human Interaction, Animal-Assisted Therapy, and AIBO-Assisted Therapy on Long-Term Care Residents with Dementia. Anthrozoös 2009; 22(1): 43-57.

Le Galès C. Fragilité et vulnérabilité au prisme des capabilités. In Sirven N et Bourgueil Y (eds.). La prévention de la perte d'autonomie. La fragilité en questions. Apports, limites et perspectives. Actes du séminaire LIRAES-IRDES, Paris, March 2014. Les rapports de l'IRDES 2016 ; 563. 113 p. January 2016. Pp 43-52.

Lekeu F, Wojtasik V, Van der Linden M, Salmon E. Training early Alzheimer patients to use a mobile phone. Acta Neurol Belg 2002; 102(3): 114-21.

Lyons BE, Austin D, Seelye A, Petersen J, Yeargers J, Riley T, Sharma N, Mattek N, Dodge H, Wild K, Kaye JA. Pervasive computing technologies to continuously assess Alzheimer's disease progression and intervention efficacy. Front. Aging Neurosci 2015. http://dx.doi.org/10.3389/fnagi.2015.00102.

Malinowsky C, Nygård L, Kottorp A. Psychometric evaluation of a new assessment of the ability to manage technology in everyday life. Scand J Occup Ther 2011; 18(1): 2635 .

Malinowsky C, Kottorp A, Patomella AH, Rosenberg L and Nygård L. Changes in the technological landscape over time: Relevance and difficulty levels of everyday technologies as perceived by older adults with and without cognitive impairment. Technol Disabil 2015; 27(3): 91-101.

Manera V, Chapoulie E, Bourgeois J, Guerchouche R, David R, Ondrej J, Drettakis G, Robert P. A Feasibility Study with Image-Based Rendered Virtual Reality in Patients with Mild Cognitive Impairment and Dementia. PloS One 2016; 11(3): e0151487.

McCreadie C, Tinker A. The acceptability of assistive technology to older people. Ageing and Society 2005; 25(1): 91-110. www.demcare.eul, accessed July 20 ${ }^{\text {th }}, 2016$.

Meiland FJ, Bouman AI, Sävenstedt S, Bentvelzen S, Davies RJ, Mulvenna MD, Nugent CD, Moelaert F, Hettinga ME, Bengtsson JE, Dröes RM. Usability of a new 
electronic assistive device for community-dwelling persons with mild dementia. Aging Ment Health 2012;16(5): 584-591.

Mental Welfare Commission for Scotland. Decisions about technology. Principles and guidance on good practice when considering the use of telecare and assistive technology for people with dementia, learning disability and related disorders. September 2015.

Morgan J. Gaming for dementia research: a quest to save the brain. Lancet, July $8^{\text {th }}$, 2016.

Mordoch E, Osterreicher A, Guse L, Roger K, Thompson G. Use of social commitment robots in the care of elderly people with dementia: a literature review. Maturitas 2013; 74(1):14-20.

Moyle W, Jones C, Dwan T, Petrovich T. Effectiveness of a Virtual Reality Forest on People With Dementia: A Mixed Methods Pilot Study. Gerontologist 2017; doi: 10.1093/geront/gnw270.

NHS Scotland, The Scottish Government, Alzheimer Scotland, Scottish Fire and Rescue Service, Tunstall, Tynetec. Technology Charter for People Living with Dementia in Scotland. $30^{\text {th }}$ November 2015.

www.alzscot.org/assets/0002/0289/Technology_Charter_for_People_with_Dementia_ $i$

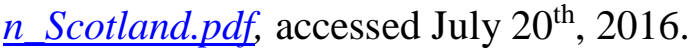

Niemeijer AR, Depla MF, Frederiks BJ, Hertogh CM. The experiences of people with dementia and intellectual disabilities with surveillance technologies in residential care. Nurs Ethics 2015; 22(3): 307-320.

Nonaka Y, Sakai Y, Yasuda K, Nakano Y. Towards assessing the communication responsiveness of people with dementia. Proceedings of the $12^{\text {th }}$ International Conference on Intelligent Virtual Agents. 2012. Berlin: Springer Verlag. ISBN 978-3642-33196-1. pp 496-498.

Nuffield Council of Bioethics. Dementia: ethical issues. 2009. Cambridge: Cambridge Publishers Ltd. 209 p. ISBN: 978-1-904384-20-5.

Nygård L, Kottorp A, Rosenberg L. Making use of research: clinical views on an evaluation of everyday technology use. Scand J Occup Ther 2015; 22(1): 24-32.

Nygård L, Pantzar M, Uppgard B, Kottorp A. Detection of activity limitations in older adults with MCI or Alzheimer's disease through evaluation of perceived difficulty in use of everyday technology: a replication study. Aging Ment Health 2012; 16(3):361-71.

Patomella AH, Kottorp A, Malinowsky C, Nygård L. Factors that impact the level of difficulty of everyday technology in a sample of older adults with and without cognitive impairment. Technol Disabil 2011; 23(4): 243-250.

Patomella AH, Kottorp A, Nygård L. Design and Management Features of Everyday Technology That Challenge Older Adults. Br J Occup Ther 2013; 78(9): 390-398. 
Petonito G, Muschert GW, Carr DC, Kinney JM, Robbins EJ, Brown JS. Programs to locate missing and critically wandering elders: a critical review and a call for multiphasic evaluation. Gerontologist. 2013; 53(1):17-25.

Phills JA, Deiglmeier K, Miller DT. Rediscovering Social Innovation. Stanford Soc Innov Rev 2008; 6(4): 34-43.

Pino M, Boulay M, Jouen F, Rigaud AS. "Are we ready for robots that care for us?" Attitudes and opinions of older adults toward socially assistive robots. Front Aging Neurosci 2015; 7:141. doi: 10.3389/fnagi.2015.00141.

Porter M. Competitive Advantage: Creating and Sustaining Superior Performance. 1985. New York.: Free Press. 557 p. ISBN : 978-0684841465.

Porter M. What Is Value in Health Care? N Engl J Med 2010; 363:2477-2481.

Raz L, Knoefel J, Bhaskar K. The neuropathology and cerebrovascular mechanisms of dementia. J Cereb Blood Flow Metab 2016; 36: 172-186.

Rizzo AS, Kim GJ. A SWOT Analysis of the Field of Virtual Reality Rehabilitation and Therapy. Presence 2005; 14(2): 119-146.

Robert PH, König A, Amieva H, Andrieu S, Bremond F, Bullock R, Ceccaldi M, Dubois B, Gauthier S, Kenigsberg PA, Gauthier S, Kenigsberg PA, Nave S, Orgogozo JM, Piano J, Benoit M, Touchon J, Vellas B, Yesavage J, Manera V. Recommendations for the use of Serious Games in people with Alzheimer's Disease, related disorders and frailty. Front Aging Neurosci 2014; 6: 54. doi: 10.3389/fnagi.2014.00054.

Rosenberg L, Nygård L. Learning and using technology in intertwined processes: A study of people with mild cognitive impairment or Alzheimer's disease. Dementia (London) 2014; 13(5): 662-677.

Rosenberg L, Kottorp A, Winblad B, Nygård L. Perceived difficulty in everyday technology use among older adults with or without cognitive deficits. Scand J Occup Ther 2009; 16(4): 216-226.

Royal Commission on Long Term Care. With Respect to Old Age: Long Term Care Rights and Responsibilities. Cm 4192-I. March 1999.

Ryd C, Nygård L, Malinowsky C, Öhman A, Kottorp A. Can the everyday technology use questionnaire predict overall functional level among older adults with mild cognitive impairment or mild-stage Alzheimer's disease? - a pilot study. Scand J Caring Sci 2016; doi:10.1111/scs.12330.

Sacco G, Joumier V, Darmon N, Dechamps A, Derreumaux A, Lee JH, Piano J, Bordone N, Konig A, Teboul B, David R, Guerin O, Bremond F, Robert P. Detection of activities of daily living impairment in Alzheimer's disease and mild cognitive impairment using information and communication technology. Clin Interv Aging 2012; 7: 539-549.

Sato M. Ninchisho ni natta watashi ga tsutaetai koto ("The Message I, as a Dementia Sufferer, Want to Tell”) Otsuki Shoten. November 2014. ISBN: 978-4-2723-6082-6. 207 p. $\quad$ www.japantimes.co.jp/news/2016/01/03/national/social-issues/options- 
available-mitigate-dangers-living-alone-dementia/\#.V45fJlSLQ-U. Accessed July 19th, 2016.

Schulz R, Beach SR, Matthews JT, Courtney K, De Vito Dabbs A, Mecca LP. Caregivers' willingness to pay for technologies to support caregiving. Gerontologist 2015; doi:10.1093/geront/gnv033.

Siegel C, Hochgatterer A, Dorner TE. Contributions of ambient assisted living for health and quality of life in the elderly and care services - a qualitative analysis from the experts' perspective of care service professionals. BMC Geriatrics 2014; 14:112.

Span M, Hettinga M, Vernooij-Dassen M, Eefsting J, Smits C. Involving People with Dementia in the Development of Supportive IT applications: a Systematic Review. Ageing Res Rev 2013; 12(2):535-51.

Span M, Smit C, Jukema J, Groen-van de Ven L, Janssen R, Vernooij-Dassen M, Eefsting J, Hettinga M. An Interactive Web Tool for Facilitating Shared DecisionMaking in Dementia-Care Networks: A Field Study. Front Aging Neurosci 2015; 7: 128. doi: 10.3389/fnagi.2015.00128.

Stokes G, Kousoulis A. What is truth ? Dilemmas when two realities meet. J Dementia Care 2017; 25(2): 24-26.

Sugihara T, Fujinami T, Phaal R, Ikawa Y. A technology roadmap of assistive technologies for dementia care in Japan. Dementia 2015; 14(1): 80-103.

Swaffer K. Dementia stigma, language, and dementia-friendly. Dementia (London) 2014; 13(6): 709-716.

Tanaka M, Ishii A, Yamano E, Ogikubo H, Okazaki M, Kamimura K, Konishi Y, Emoto $\mathrm{S}$, Watanabe $\mathrm{Y}$. Effect of a human-type communication robot on cognitive function in elderly women living alone. Med Sci Monit 2012; 18(9):CR550-557.

Teipel S, Babiloni C, Hoey J, Kaye J, Kirste T, Burmeister OK. Information and communication technology solutions for outdoor navigation in dementia. Alz Dement 2016; 12: 695-707.

Tellez J, Krishnakumar J, Bungener M, Le Galès C. Capability deprivation of people with Alzheimer's disease: An empirical analysis using a national survey. Soc Sci Med 2016; 151: 56-68.

van der Roest HG, Meiland FJ, Comijs HC, Derksen E, Jansen AP, van Hout HP, Jonker $\mathrm{C}$, Dröes RM. What do community-dwelling people with dementia need? A survey of those who are known to care and welfare services. Int Psychogeriatr 2009; 21(5): 949965.

Williamson T, Kirley A. What is Truth? An Inquiry about Truth and Lying in Dementia Care. London: Mental Health Foundation 2014. 50 p.

Woodall J, Suur C, Kinsella K and Bunyan AM. An independent evaluation of 'dementia diaries'. Leeds Beckett University. 2016. 
World Health Organisation. Towards a common language for functioning, disability and health ICF, World Health Organisation, Geneva, 2002

World Health Organisation. Towards a common language for functioning, disability and health ICF. 2002

Yang YT, Kels CG. Does the shoe fit? Ethical, legal and policy considerations of global positioning systeme shoes for individuals with Alzheimer's Disease. J Am Geriatr Soc 2016; doi: 10.1111/jgs.14265. 


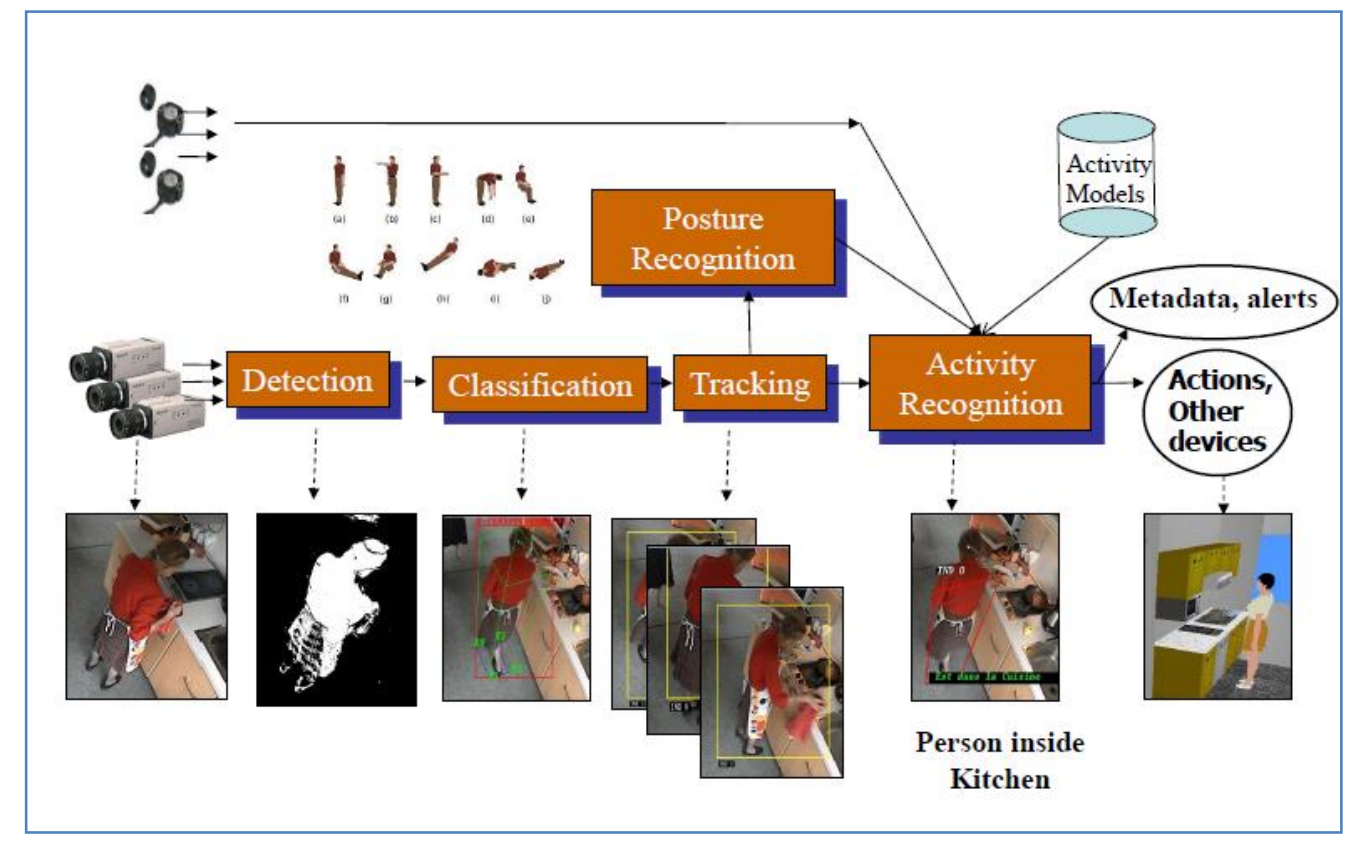

Figure 1. Ecological assessment of daily life activities and detection of accidents in the Dem@Care project. 


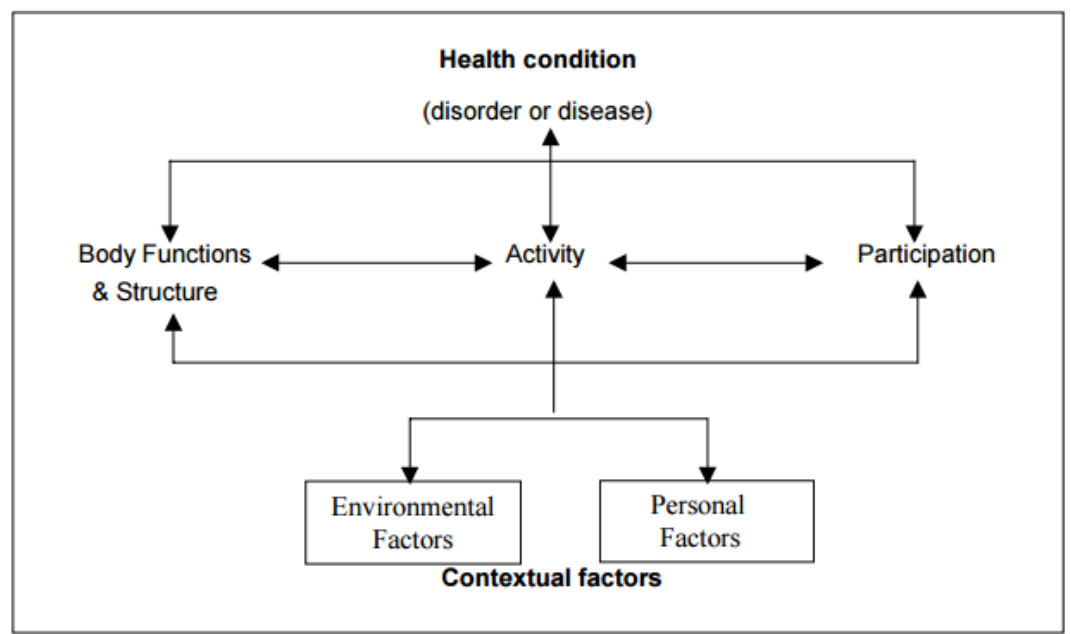

Fig. 2. The WHO biopsychosocial model of disability 
Table 1. Three ways in which assistive technology can help people with dementia (Technology Charter for People Living with Dementia in Scotland, 2015).

\begin{tabular}{|c|c|c|}
\hline $\begin{array}{l}\text { a) Enabling and } \\
\text { empowering }\end{array}$ & b) Health and well-being & $\begin{array}{l}\text { c) Safety and } \\
\text { independence }\end{array}$ \\
\hline $\begin{array}{l}\text { To support what people } \\
\text { can, and want to do for } \\
\text { themselves. }\end{array}$ & $\begin{array}{l}\text { To maximise confidence, } \\
\text { capacity and capability of } \\
\text { the individual to self- } \\
\text { manage their dementia } \\
\text { and any other health } \\
\text { conditions they may } \\
\text { have. }\end{array}$ & $\begin{array}{l}\text { To provide individualised } \\
\text { solutions to concerns } \\
\text { about safety, security and } \\
\text { independence. }\end{array}$ \\
\hline $\begin{array}{l}\text { To increase choice and } \\
\text { opportunity. }\end{array}$ & $\begin{array}{l}\text { To support physical and } \\
\text { mental health and } \\
\text { wellbeing through the use } \\
\text { of technology enabled } \\
\text { care. }\end{array}$ & $\begin{array}{l}\text { To reduce risk of fire and } \\
\text { prevent accidents. }\end{array}$ \\
\hline $\begin{array}{l}\text { To support what is } \\
\text { important to the person } \\
\text { with dementia and their } \\
\text { families and carers. }\end{array}$ & $\begin{array}{l}\text { To help create or } \\
\text { maintain routine. }\end{array}$ & $\begin{array}{l}\text { To support people with } \\
\text { dementia to walk freely } \\
\text { and safely both indoors } \\
\text { and outdoors. }\end{array}$ \\
\hline $\begin{array}{l}\text { To support the ordinary } \\
\text { everyday activities of } \\
\text { daily life. }\end{array}$ & $\begin{array}{l}\text { To support the search for } \\
\text { information, advice, } \\
\text { support and help. }\end{array}$ & $\begin{array}{l}\text { To encourage going out } \\
\text { and about and reduce the } \\
\text { risk of being lost or the } \\
\text { risks associated with being } \\
\text { lost. }\end{array}$ \\
\hline $\begin{array}{l}\text { To reduce isolation and } \\
\text { disconnection from } \\
\text { personal and social } \\
\text { communities. }\end{array}$ & $\begin{array}{l}\text { To reduce the risks } \\
\text { associated with falls and } \\
\text { disorientation. }\end{array}$ & $\begin{array}{l}\text { To facilitate the person } \\
\text { with dementia to } \\
\text { communicate with a } \\
\text { remote partner in care } \\
\text { should clarity or } \\
\text { reassurance be required. }\end{array}$ \\
\hline $\begin{array}{l}\text { To maximise existing } \\
\text { skills and abilities and } \\
\text { support the development } \\
\text { of new skills. }\end{array}$ & $\begin{array}{l}\text { To support reminiscence } \\
\text { and life story work. }\end{array}$ & $\begin{array}{l}\text { To automatically alert a } \\
\text { remote partner in care to } \\
\text { the real time occurrence of } \\
\text { a risk to the person or } \\
\text { property }\end{array}$ \\
\hline $\begin{array}{l}\text { To assist with } \\
\text { communication and } \\
\text { reduce the impact of } \\
\text { sensory loss. }\end{array}$ & $\begin{array}{l}\text { To support medication } \\
\text { regimes. }\end{array}$ & \\
\hline $\begin{array}{l}\text { To support memory, } \\
\text { reasoning, judgement and } \\
\text { decision making. }\end{array}$ & & \\
\hline $\begin{array}{l}\text { To maintain social } \\
\text { networks and enhance } \\
\text { personal connection } \\
\text { through social and digital } \\
\text { media. }\end{array}$ & & \\
\hline
\end{tabular}


Table 2. Values, principles, rights and obligations: the Technology Charter for people living with dementia in Scotland

\begin{tabular}{|c|c|c|}
\hline Values and principles & $\begin{array}{c}\text { People living with } \\
\text { dementia have a right to: }\end{array}$ & Partners in care need to: \\
\hline $\begin{array}{l}\text { - Practice and service } \\
\text { provision is rights-based, } \\
\text { personalised and free from } \\
\text { discrimination. } \\
\text { - Unpaid carers and families } \\
\text { are recognised and valued } \\
\text { as equal partners in care. } \\
\text { - Information and advice } \\
\text { about technology is } \\
\text { available in clear everyday } \\
\text { language and in a variety } \\
\text { of formats. } \\
\text { - Routes and access to } \\
\text { technology are ethical, } \\
\text { equitable, simple, } \\
\text { understandable and user- } \\
\text { friendly. } \\
\text { - Consideration of } \\
\text { technology is embedded at } \\
\text { all key points in the } \\
\text { integrated dementia care } \\
\text { pathway. } \\
\text { - Technology augments - } \\
\text { but does not replace - } \\
\text { human intervention. }\end{array}$ & $\begin{array}{l}\text { - Enjoy equity of service } \\
\text { and service provision. } \\
\text { - Participate in decisions } \\
\text { that affect them. } \\
\text { - Feel safe, take positive } \\
\text { risks and enjoy freedom } \\
\text { of choice. } \\
\text { - Have their strengths and } \\
\text { experience } \\
\text { acknowledged and used } \\
\text { to maintain and develop } \\
\text { skills. } \\
\text { - Attain and maintain } \\
\text { maximum independence, } \\
\text { health and wellbeing. } \\
\text { - Enjoy access to } \\
\text { recreational, leisure and } \\
\text { cultural life in their } \\
\text { community. } \\
\text { - Have a strong clear voice }\end{array}$ & $\begin{array}{l}\text { - Have the health, safety } \\
\text { and wellbeing of people } \\
\text { living with dementia at } \\
\text { the heart of what they do. } \\
\text { - Share information and } \\
\text { data with all other } \\
\text { partners in care who } \\
\text { support people to live } \\
\text { well with dementia. } \\
\text { - Value the knowledge and } \\
\text { experience of those } \\
\text { living with dementia. } \\
\text { - Include people living } \\
\text { with dementia in the } \\
\text { design and development } \\
\text { of technology enabled } \\
\text { dementia care. } \\
\text { - Support positive risk } \\
\text { taking and agree and } \\
\text { share risk and } \\
\text { responsibility. } \\
\text { - Ensure technology is } \\
\text { considered and included } \\
\text { in the design of internal } \\
\text { and external living } \\
\text { environments. } \\
\text { - Be confident that } \\
\text { everyone involved in } \\
\text { delivering care and } \\
\text { support is aware of, and } \\
\text { up-to-date with, the } \\
\text { positive benefits of } \\
\text { technology. }\end{array}$ \\
\hline
\end{tabular}


Table 3. Purpose of assistive technology for people with dementia:

Domains of everyday life activity using the standards of the WHO International Classification of Functioning, Disability and Health (2002)

\begin{tabular}{|l|}
\hline Domains of daily life activity \\
\hline General tasks and demand \\
\hline Communication \\
\hline Mobility \\
\hline Self-care \\
\hline Domestic life \\
\hline Interpersonal interactions and relationships \\
\hline Community, social and civic life \\
\hline Recreation and leisure \\
\hline
\end{tabular}


Table 4. The economic value chain of assistive technology for people with dementia : processes involve multiple professionals from many different cultures, with no clear identification of who is concerned with individual needs and technology use assessment

\begin{tabular}{|c|c|}
\hline Process & Stakeholders \\
\hline Research & $\begin{array}{l}\text { Engineers } \\
\text { Expert profesionals } \\
\text { People with dementia } \\
\text { Caregivers }\end{array}$ \\
\hline Industrial development & $\begin{array}{l}\text { Engineers } \\
\text { Expert professionals }\end{array}$ \\
\hline Production & Engineers \\
\hline Marketing & $\begin{array}{l}\text { Business to business marketers } \\
\text { Business to consumer marketers } \\
\text { Opinion leaders } \\
\text { Journalists } \\
\text { Social media users }\end{array}$ \\
\hline Distribution & $\begin{array}{l}\text { Specialized vendors } \\
\text { e-commerce vendors } \\
\text { Associations } \\
\text { Central purchasers }\end{array}$ \\
\hline Installation and user assistance & $\begin{array}{l}\text { People with dementia } \\
\text { Family caregivers } \\
\text { Professional caregivers } \\
\text { Assistance professionals }\end{array}$ \\
\hline Prescription & $\begin{array}{l}\text { Family and friends } \\
\text { Health and social care professionals } \\
\text { People with dementia }\end{array}$ \\
\hline Purchase (co-payment) & $\begin{array}{l}\text { Individuals } \\
\text { Social welfare } \\
\text { Insurers } \\
\text { Local governments }\end{array}$ \\
\hline Device use & $\begin{array}{l}\text { People with dementia } \\
\text { Family caregivers } \\
\text { Professional caregivers }\end{array}$ \\
\hline Data sharing & $\begin{array}{l}\text { Engineers } \\
\text { Data managers } \\
\text { Health and social care professionals } \\
\text { Families } \\
\text { Control authorities }\end{array}$ \\
\hline Device maintenance & $\begin{array}{l}\text { Technicians } \\
\text { Operators } \\
\text { Maintenance companies } \\
\end{array}$ \\
\hline Technology assessment & $\begin{array}{l}\text { Associations } \\
\text { Opinion leaders } \\
\text { Professional societies } \\
\text { Operators } \\
\text { Central puchasers } \\
\text { Public funders } \\
\end{array}$ \\
\hline
\end{tabular}

